\title{
The energy and carbon footprint of the ICT and E\&M sector in Sweden 1990-2015 and beyond
}

\author{
Jens Malmodin \\ Ericsson Research \\ Ericsson $\mathrm{AB}$ \\ Stockholm, Sweden \\ jens.malmodin@ericsson.com
}

\author{
Dag Lundén \\ Telia Company AB \\ Stockholm, Sweden \\ Dag.Lunden@teliacompany.com
}

\begin{abstract}
This paper is a detailed study of the energy and carbon footprint of the ICT (Information and Communication Technology) and E\&M (Entertainment and Media) sectors in Sweden both historically, currently (2015) and beyond. It is a follow up to a study of ICT in Sweden 2010.

Several studies predict that the ICT and E\&M sectors will continue to increase their energy and carbon footprints, and in the case of ICT exponentially similar to the data traffic increase. This study shows that in fact the opposite trend is seen in Sweden, the footprints have started to decrease despite a continuing exponential increase in data traffic. The study is based on a large share of measured data and Sweden is worldleading in many ICT and E\&M metrics, thus it can be seen as an exellent case study and guide on how ICT and E\&M will develop globally in the future.
\end{abstract}

This study shows that the energy and carbon footprints of the ICT and E\&M sectors have decreased from a peak at around 2010. The increasing trend of using tablets and smartphones with a low energy consumption (small screens) instead of PCs and TVs is an important contributing factor. Despite that the sales of PCs and TVs have decreased by nearly $20 \%$, the embodied carbon footprint from their manufacturing processes abroad are still the largest source of ICT related carbon emissions in Sweden. The carbon footprint related to operation is low due to the low-carbon Swedish electricity mix.

Based on current trends and network plans, it can be forecasted that the energy and carbon footprints of the ICT and the E\&M sectors will continue to decrease at least until 2020.

Keywords-ICT, ICT networks, ICT sector, energy footprint, carbon footprint

\section{INTRODUCTION, BACKGROUND AND SCOPE}

Global warming has emerged as the biggest threat to our society. In 2016, experts associated with the World Economic Forum ranked global warming as the no.1 threat to society and our economy [1]. An increased awareness of these facts but also of actions to reduce the energy and carbon footprints is necessary for every nation, region, community, company, organization, and even person. This study is a follow-up to a study of the ICT sector in Sweden 2010 [2] and another study that presented historical data for ICT in Sweden 1990-2010 [3].

The used scope for the ICT sector is the same as in the former studies and includes a large variety of ICT user equipment, access networks, data transmission and IP core networks, network operators and their activities, enterprise networks (in e.g. offices) and data centers.

The E\&M sector has been added to the scope and includes TVs and TV peripherals (e.g. game consoles and home theater systems), audio, video, camera and other consumer electronics plus paper media, see Figure 1. In this study, also ICT services and E\&M content production have been investigated. The E\&M sector was included and defined in the study of the ICT sector globally in 2007 [4] but was not included in the study of ICT in Sweden 2010.

Regarding the scope only the GeSi studies [5-7] come close but do not include the E\&M sector, are on a global level and of less detail. There exist a few other recent national studies of the use stage energy consumption of ICT, e.g. [8] and [9]. These studies do not include the production stage and have a more narrow scope but are of high quality and presents decreasing energy consumption.

Sweden is world-leading in many ICT and E\&M metrics and by that relevant to study. Sweden has the highest data traffic per capita in the world, only Finland has a slightly higher mobile data traffic [10]. The total number of PCs, tablets and smartphones per capita (2.7) is also among the highest in the world. There is also a long tradition of collecting (requiring) information from people, businesses and organizations and to make data public available, see Table I.

The main goal of the study is to give an updated overview of the Swedish ICT and E\&M sector's energy and carbon footprints over time. It was not possible in this paper to go into more detail for specific parts of the ICT and E\&M sectors due to the limited format. However, there is a strong need to share the overall results as they show something very important: the former trend of growing footprints for both the ICT and E\&M sectors have changed and both the energy and carbon footprints are now shrinking. This is despite the fact that more devices than ever are in use and data traffic continues to increase exponentially. The findings are in contrast to other studies that have projected that the ICT sector's footprint will continue to grow and even, in some future scenarios, grow exponentially similar to data traffic, e.g. [11] and [12].

Since Sweden is in the forefront of ICT development it's reasonable to expect a similar development globally. Decreasing global sales of PCs and TVs and flat server sales (market analysts, e.g. IDC) is a good indication of this change. 

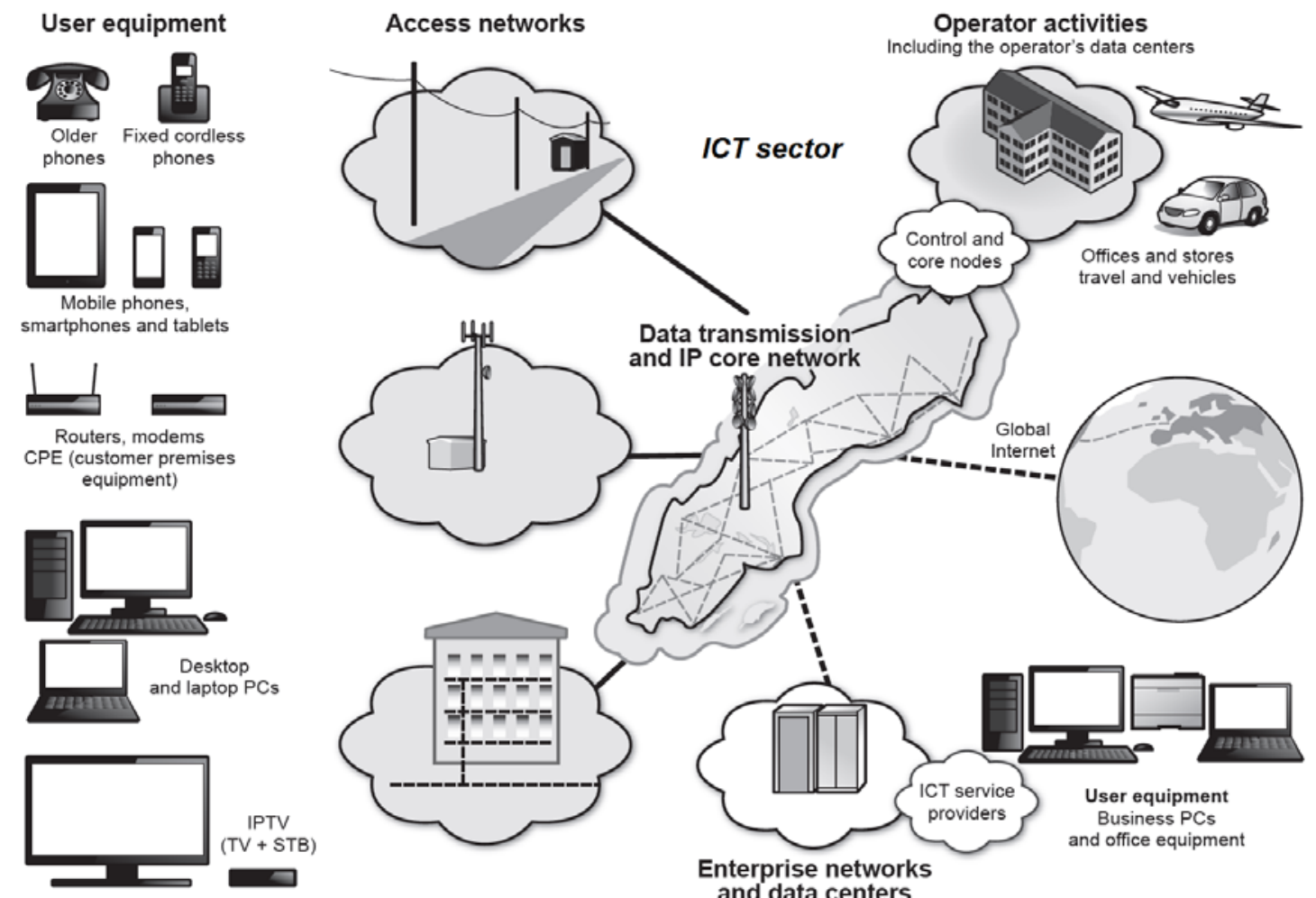
and IP core network

Figure 1 Scope of the ICT sector and the E\&M sector. The figure is an updated version of a figure first presented in [1].

\section{METHODOLOGY, DEFINITIONS AND DATA SOURCES}

Abbreviations, terms and main data sources (reoccurring reports) described in Table I that are used throughout the paper.

TABLE I. ABBREVIATIONS, TERMS AND MAIN DATA SOURCES

\begin{tabular}{|c|}
\hline Abbreviations, terms and their description \\
\hline $\begin{array}{l}\text { ICT = Information and Communication Technology } \\
\text { E\&M =Entertainment and Media }\end{array}$ \\
\hline $\begin{array}{l}\text { PSTN = Public Switched Telephony Network, FTTx = Fiber To The } \mathrm{x}(\mathrm{x}= \\
\text { home, building etc.), CPE = Customer Premises Equipment, } \\
\text { DSL = Digital Subscriber Line }\end{array}$ \\
\hline IP = Internet Protocol, VoIP = Voice over IP, BB = Broadband \\
\hline GSM/WCDMA/LTE = 2G/3G/4G technology/standard, G = Generation \\
\hline $\begin{array}{l}\mathrm{EF}=\text { Energy Footprint, } \mathrm{CF}=\text { Carbon Footprint, } \mathrm{GHG}=\text { Greenhouse Gas, } \\
\text { tonne, ktonne etc. means tonne, ktonne etc. } \mathbf{C O}_{2} \text {-eq etc. (carbon footprint) }\end{array}$ \\
\hline Main data sources: abbreviation, name and description \\
\hline $\begin{array}{l}\text { PTS, Swedish Post and Telecom Authority, The Swedish } \\
\text { Telecommunications Market (half year and full year reports), latest: [13-14] }\end{array}$ \\
\hline $\begin{array}{l}\text { SCB, Statistics Sweden, Telecommunications (annual statistics report, in } \\
\text { cooperation with PTS), latest: [15], Population statistics, latest: [16] }\end{array}$ \\
\hline EM, Swedish Energy Authority, several important energy studies (see text) \\
\hline $\begin{array}{l}\text { EB/MTB, Electronics Association / Mobile Phones Association, Quarterly } \\
\text { sale statistics for all consumer electronics, latest: [17] }\end{array}$ \\
\hline $\begin{array}{l}\text { MRTV, Swedish Radio and TV Authority, Media Development (annual } \\
\text { report), latest: [18] }\end{array}$ \\
\hline SI, Swedish Forest Industries Federation, Annual report, latest: [19] \\
\hline $\begin{array}{l}\text { AV, Swedish Work Environment Authority, The Work Environment (bi- } \\
\text { annual report including PC usage at work), latest: [20] }\end{array}$ \\
\hline
\end{tabular}

Apart from the 2010 study [2], there are a number of other sources that have been vital for this paper. These are mentioned in Table I however a few deserve additional explanation. The Swedish Energy Authority (EM) did a unique study in 2008 of 400 Swedish households measuring the electricity consumption of individual devices over a whole year [21]. In addition the EM has since 1990 performed long-term studies on the total energy consumption of households, non-industrial buildings (e.g. offices) and industrial buildings. They have also performed detailed investigations of offices including data centers in 1990 and 2005. These studies form the basis of the understanding of the historical energy consumption of the ICT sector in offices and in data centers beyond Ericsson and Telia Company (hereafter "Telia") operations. This is described more in [2], [3] and [22].

The method applied in this study is similar to the 2010 study and can be summarized in five steps, see Table II.

\section{TABLE II. SUMMARY OF METHODOLOGICAL STEPS}

1 Create detailed top-down measurements and bottom-up models of network operation and other activities (see Table IV).

2 Extrapolate network equipment to a total for the country based on network measurements and national statistics (see Table I). Other external non-public information can also be used when available.

3 Determine number of devices put on the market, in use and their usage and energy consumption using national statistics and user surveys.

$4 \quad$ Use LCA data from own performed LCA studies and identify the most appropriate external LCA studies to be able to estimate the embodied footprint of networks and user devices (see section VI).

$5 \quad$ Combine these results together with similar studies into a historical context and use this to make a sound future projection. 
Important key data for Sweden and the ICT and E\&M sectors in Sweden is presented in Table III below.

TABLE III. SWEDEN / ICT / E\&M KEY DATA 2010/2015

\begin{tabular}{|l|c|c|}
\hline Key data [millions/Mtonnes] & $\mathbf{2 0 1 0}$ & $\mathbf{2 0 1 5}$ \\
\hline Inhabitants & 9.4 & 9.8 \\
\hline Households & 4.7 & 4.8 \\
\hline GHG emissions, official & 65 & 55 \\
\hline${\text { GHG emissions, consumption }{ }^{1}}^{\text {PSTN subscriptions (subs) }}$ & 122 & $\sim 115$ \\
\hline PST & 4.7 & 1.9 \\
\hline VoIP subs & 0.7 & 1.8 \\
\hline Mobile telephony and BB subs & 10.5 & 12.2 \\
\hline Mobile BB data (only) subs & 1.7 & 2.2 \\
\hline Mobile M2M subs (data) & 2.0 & 6.5 \\
\hline xDSL fixed BB subs/lines & 1.7 & 1.2 \\
\hline Cable-TV fixed BB subs & 0.55 & 0.6 \\
\hline FTTx fixed BB subs/lines & 0.55 & 1.5 \\
\hline Cable-TV subs/lines & 3.3 & 3.1 \\
\hline IPTV subs & 0.45 & 0.9 \\
\hline Other TV subs & 1.4 & 1.1 \\
\hline
\end{tabular}

Figures used in the study are for the year 2015 unless explicitly stated. Figures that quantify network sites and nodes, subscriptions and equipment in active use are per mid-year to match annual figures for e.g. energy consumption and data traffic. When data traffic has been derived from data rates the average data rate in 2015 has been used.

\section{THE ICT SECTOR IN SWEDEN 2015}

\section{A. Mobile phones, smartphones and M2M}

The sales of mobile phones are in average about 3.8 million per year for the period 2010-2015. Smartphones represent about $85 \%$ of all mobile phones in use and constitute more than $90 \%$ of sales since 2013 . The average life time per phone measured as "phones put on market / subscriptions" each year was 3 years (up to 2010) but is now slowly increasing to about 3.3 years. The life time is probably slightly longer as more phones are reconditioned (especially B2B phones) and reused in other countries however reliable statistics are missing.

The number of M2M subscriptions and devices has grown from about 2 to 6.5 million and a large share is smart energy meters in households. Even if only the communication module itself is included as ICT in this study the estimated total energy consumption of all M2M communication modules is quite high, about $110 \mathrm{GWh}$, which can be compared to the estimated 47 GWh for all 12.2 million mobile phones in use.

\section{B. PCs and tablets}

The number of PCs sold per year has been around 1.9 million since 2010. It is estimated that there exist about 9.6 million PCs in active use today. About 9.7 million PCs have been sold during the last 5 years and the average life time can be estimated to about 5 years applying the same methodology as for mobile phones. The number of tablets sold (2011-2015) in Sweden is about 5.5 million and assuming that the majority of them, about 5 million, are still in active use.

A number of important trends can be seen in the annual sale statistics and user surveys in Sweden: growing share of laptops, improved energy performance, increased number and usage of tablets and smartphones replacing PC usage, and improved production processes overall (indicated by lower prices).

\section{Telia network operation and operator activities}

Top-down and bottom-up measurements and estimates by Telia form the basis for the network operation part. More than 10000 physical sites and more than 100000 equipment data specifications contributed with top-down and bottom-up energy data for 2015 and the results are shown in Table IV.

TABLE IV. TELIA ENERGY DATA 2010/2015

\begin{tabular}{|c|c|c|}
\hline Electricity / other energy [GWh] & 2010 & 2015 \\
\hline Fixed telephony (PSTN and VoIP) & 132 & $79(-39 \%)$ \\
\hline PSTN access lines (1.9 M subs 2015) & 86 & 65 \\
\hline PSTN dedicated transmission & 20 & 11 \\
\hline PSTN exchanges / core nodes & 24 & 0.6 \\
\hline VoIP core nodes ( $0.75 \mathrm{M}$ subs) & 1.7 & 1.9 \\
\hline Fixed BB data & 34 & $61(+79 \%)$ \\
\hline xDSL fixed BB access lines (0.95 M) & 34 & 38 \\
\hline Cable-TV fixed BB access lines & minor & minor \\
\hline FTTx fixed BB access lines (0.55 M) & minor & 23 \\
\hline Mobile telephony and mobile BB data & 99 & $150(+50 \%)$ \\
\hline 2G (GSM) base stations & 57 & 48 \\
\hline 3G (WCDMA) base stations ${ }^{1}$ & 30.5 & 51 \\
\hline 4G (LTE) base stations & minor & 38 \\
\hline 2G/3G/4G dedicated transmission & 7 & 10 \\
\hline $\begin{array}{l}\text { 2G/3G/4G BSCs,RNCs and other mobile } \\
\text { core nodes }\end{array}$ & 3.7 & 3 \\
\hline Operator activities, electricity & 66 & $43(-39 \%)$ \\
\hline Offices & 26 & 23 \\
\hline Stores & 2.6 & 2.2 \\
\hline Own data rooms/centers & 37 & 18 \\
\hline Data transport and IP core network & 84 & $73(-13 \%)$ \\
\hline Data transport/transmission links & 62 & 42 \\
\hline $\begin{array}{l}\text { IP edge/metro/core switches/routers and } \\
\text { high capacity links (DWDM) }\end{array}$ & 22 & 31 \\
\hline TOTAL electricity, adjusted & 415 & $406(-2 \%)$ \\
\hline TOTAL electricity, measured & 410 & $402(-2 \%)$ \\
\hline Operator activities, other energy $^{2}$ & 136 & $107(-21 \%)$ \\
\hline Buildings, employee travel ${ }^{2}$ & 63 & 16 \\
\hline Vehicle fleets, transports ${ }^{2}$ & 62 & 68 \\
\hline Network construction and deployment ${ }^{2}$ & 11 & 22.5 \\
\hline
\end{tabular}

Note: All figures have been adjusted for colocation (other operator's equipment subtracted) and own equipment that are not included in own electricity metering (colocated elsewhere, added based on measured similar equipment).

${ }^{1}$ Telia's share of the nationwide $3 \mathrm{G}$ network shared with Tele2 plus own sites.

${ }^{2}$ Estimate based on reported $\mathrm{CO}_{2}$ emissions and on average $0.26 \mathrm{~kg} \mathrm{CO}_{2} / \mathrm{kWh}$ for oil based fuels (heat value). Note that this other primary energy cannot be compared directly to the electricity consumption or secondary electric energy as it requires about 2 units of primary energy in Sweden to produce 1 unit of electric energy (the ratio in the world is about 3:1 on average). 


\section{Mobile access networks}

One large difference between the former study (2010) and now (2015) is that three nationwide 4G networks have been deployed covering approximately $90 \%$ of the population. The 2G and 3G networks have been built out and modernized. Two $2 \mathrm{G}$ networks have also been merged into one. The total energy consumption for mobile access networks have increased with about 150 GWh and there are now about 50000 radio base station node equipment installed at about 20000 physical sites. About $1 / 3$ of the physical sites have an own antenna tower.

\section{E. Fixed access networks}

Nearly 2 million PSTN lines and older exchanges have been decommissioned since 2010 which has saved about 50 GWh of electricity. Of the about 5 million remaining lines only 1.9 million lines are in active use which can be compared to the 4.7 million active lines in 2009. IP-telephony (VoIP) subscriptions have on the other hand increased from 0.7 to 1.8 million, but the required energy has decreased with about 10 GWh due to more efficient VoIP core nodes.

Fixed broadband connections have increased from 2.8 million to 3.3 million. About $45 \%$ or 1.5 million is fiber connections in 2015 compared to only 20\% in 2009 and the trend is that FTTx is replacing xDSL (1.2 million 2015). Similar to 20100.6 million Cable-TV lines are used for fixed broadband. The total energy consumption for fixed BB access has increased with about $45 \mathrm{GWh}$.

\section{F. Fixed phones and fixed CPE}

As the number of fixed telephony subscriptions (PSTN + VoIP) have decreased from 5.4 to 3.7 million (2010-2015) the use of cordless telephones have decreased proportionally. The number of CPE "boxes” related to first of all fixed BB but also to mobile BB have increased. Older modem + router setups have been replaced by "one box" gateways with improved (decreased) energy consumption. In total the energy consumption for fixed phones and CPE is about the same in 2015 as in 2010.

An active fiber termination unit is required for FTTx lines installation to make it more robust. The energy consumption for these units is estimated to 57.5 GWh in 2015.

\section{G. Operator activities}

The number of employees in direct operations (Telia and other Swedish operators) have decreased from about 19500 in 2010 to 17500 in 2015 and the number of indirect employees (services and infrastructure construction and deployment) is estimated to about 20000 . The total consumption of other energy is estimated to about $210 \mathrm{GWh}$, a decrease with about $20 \%$.

\section{H. Data transmission and IP core network}

Older transmission links and especially the so called "next last miles" ("last mile" refers to access lines) dominated the energy consumption in the 2010 study. These systems have partly been replaced and there is also continuously modernizations going on at all levels up to core routers that have decreased the energy consumption with about $10 \mathrm{GWh}$.

\section{Enterprise networks and data rooms/centers}

Local networks and office equipment are estimated to have decreased slightly in terms of total electricity consumption despite the number of office employees that is estimated to have increased from 2.1 to 2.5 million. There is no exact figure for the number of office workers and office PCs in Sweden. The number of office employee equivalents using one work-PC equivalent each has been used in this study according to the work place survey by Swedish Work Environment Authority [20]. Ericsson and Telia host offices for about 30000 people and for these detailed operational data exists.

A number of large data centers have been established in Sweden after 2010 including Facebook's mega data center in Luleå (105 GWh). In addition there exists about 10 larger data centers but none even close to as large as just Facebook's hall 1 (3 halls planned, fully built-out it will be the largest data center in the Europe/Middle East/Africa part of the world). Nearly 50 data centers are listed in the Data Center Map (see http://www.datacentermap.com/) and a few have also contributed with energy data. Improvements of existing data centers, the PUE-factor and change from local to cloud services have saved a considerable amount of energy but the DC expansion has been even larger. Data centers in Sweden are estimated to consume about 1250 GWh in 2015.

\section{J. Data traffic}

Total data traffic is defined as data traffic in and out of the core network and the various access networks. This means that data broadcasted to individual users (e.g. IPTV) is not counted per individual user but per common data stream to the access node (that data stream is on the other hand always counted even if no individual user "use" it).

Measured data traffic represents about $45 \%$ of the final estimated total. The increase since 2010 is about 6 times which equals about $35 \%$ per year. The increase is slightly higher than the growth that was estimated back in 2010 (35\% vs 30\%).

Based on Telia International Carrier data it can be estimated that about $20 \%$ of the data exchange is with other countries. In addition there is also transit data traffic that passes through Sweden to other countries in the order of $1 / 3$ of total Swedish data traffic. The energy consumption for this traffic is included in the total energy consumption (it's a very small part though).

As already mentioned in the introduction Sweden has the highest data traffic per capita in the world $(1.3 \mathrm{~TB} /$ year or about 260 HD movies a' $5 \mathrm{~GB} /$ movie, about $1 / 4$ is business data). Only Finland has slightly higher mobile data traffic per subscriber. Data traffic per capita is about 10 times higher in Sweden compared to the global average and mobile data traffic is about 7 times higher.

\section{THE E\&M SECTOR IN SWEDEN 2015}

\section{A. TVs and TV networks}

The sales of TVs have decreased with nearly $20 \%$ in numbers and about 40\% in revenue between 2010 and 2015. About $60 \%$ of TVs sold 2012-2014 was 40 inches or larger. The number of TV subscriptions has decreased but only 
slightly since 2010 and is about 5.1 million now. There are about 7.5 million TVs in active use. Only about 0.75 million TVs have been sold per year the last three years. The improvements in energy consumption of TVs have been substantial and a 50 inch TV consume similar or less electricity than an old 32 inch CRT did 15 years ago. The average life time for TVs the last 10 years can be estimated to about 8 years using the same calculation method as for mobile phones. TV and radio broadcasting and cable-TV networks consume about 185 GWh based on measurements by TV network operators.

\section{B. TV peripherals and other consumer electronics}

The sales (revenue) of other consumer electronics which include TV peripherals and other media, audio, game and camera equipment have nearly halved in (-45\%) since its top at around 2005. The number of sold audio products has also nearly been halved and the number of sold cameras has decreased by $60 \%$. In addition, new devices have also improved their energy performance.

\section{Paper used for media}

About $1 / 3$ of the 1.8 Mtonne paper consumed in Sweden is for media use including printing paper used in offices. The total carbon footprint for media paper is estimated to be between 0.15 and 0.3 Mtonne $\mathrm{CO}_{2}$-eq (0.23 Mtonne used) which is substantially lower than the carbon footprints of the ICT and E\&M sectors. Most of the GHG emissions are related to imports of paper and the CF would be only about 0.09 Mtonne $\mathrm{CO}_{2}$-eq if all paper and printing were done in Sweden. The paper consumption has decreased with about $20 \%$ in Sweden since the top consumption was reached at around year 2000. All statistics in this section comes from the Swedish forest industries annual report [19]. Note that the Swedish forests act as a carbon sink. Despite being used for wood and paper the Swedish forest grows in volume.

\section{ICT SERVICES AND E\&M CONTENT PRODUCTION}

The scope has been broadened to also include ICT services and content production as far as possible. Some ICT services were already included in the 2010 study. In 2015 the whole ICT sector in Sweden is estimated to have about 420 billion SEK in revenue and about 200000 employees [23]. When excluding employees of ICT operators, indirect operations, consumer electronic sales, business more related to exports (e.g. Ericsson) about 150000 employees remain which is used together with an estimate of the energy and carbon footprint for office workers in Sweden based on Ericsson and Telia office workers. Sweden is a large net exporter of media but at the same time a large importer of media. Media import/export can today be both physical (paper) and virtual/digital. It's not possible to measure the actual virtual/digital volumes.

\section{LIFE CyCLE ASSESSMENT (LCA)}

One of the most important unique aspects of this study is that the whole life cycle is included in the scope. Both Ericsson and Telia have about 20 years of experience performing life cycle assessments. For a detailed description of these performed LCA studies, see [2]. A number of these studies have been reused to estimate the manufacturing and deployment stages of the network. In addition new LCA's of smartphones, base station equipment and other network equipment have been carried out at Ericsson and new studies of deploying fiber access to homes and data center operations have been carried out at Telia.

\section{END OF LIFE}

The end-of-life treatment (EoLT) stage was not included in the 2010 study as such but LCA data for equipment did take EoLT and recycling of metals into account. EoLT is now included more in detail. There are about 600 larger and 10000 smaller recycling and waste collection centers and about 30 major waste recycler sites in Sweden, some of them stated as the most advanced metal recyclers in the world, e.g. Boliden/ Rönnskärsverken that recycle metals in printed circuit boards.

Beside the highest ICT usage and data traffic per capita, Sweden has also the highest collection and recycling rate of WEEE (waste of electrical and electronic equipment) in the world, about 150000 tonnes or about $15 \mathrm{~kg}$ per person and year for the period 2008-2014. Household appliances represent about half of all waste but the share is increasing.

The waste category "IT, telecom and office equipment” fits well with the definition of ICT equipment. This waste category has decreased from about 28000 ton in 2008 down to 21000 tonnes (2.2 kg per capita) in 2014. "TV, audio and video equipment" fits well with the definition of E\&M equipment. This waste category has increased from about 33000 tonnes in 2008 up to 36500 tonnes (3.8 kg per capita) in 2014.

The average amount of $\mathrm{CO}_{2}$-eq emissions has decreased from about $0.5 \mathrm{~kg} \mathrm{CO}_{2}$-eq per kg WEEE year 2000 to about 0.2 $\mathrm{kg} \mathrm{CO}_{2}$-eq according to internal investigations by Ericsson and recyclers responsible for WEEE collection, transports and processes. The total emissions can be estimated to about 12 ktonne $\mathrm{CO}_{2}$-eq. But in addition, based on metal content it can be estimated that the total $\mathrm{CO}_{2}$-eq emissions avoided by metal recycling is equal to 150 ktonne $\mathrm{CO}_{2}$-eq.

\section{RESULTS}

Detailed EF results (energy consumption during use/operation) are presented in figure 2 on the next page. PCs and TVs represent a large part of the EF together with data centers. The electricity consumption of all equipment/devices is usually key parameters in LCA and carbon footprint studies of ICT. However, due to the low-carbon Swedish electricity mix the EF plays a minor role for the CF in Sweden (see Figure 3 and 4 and related descriptions).

The CF of the Swedish ICT sector in 2015 is estimated to be about 1.4 Mtonne $\mathrm{CO}_{2}$-eq (about $140 \mathrm{~kg}$ per capita), which is about $1.2 \%$ of the overall Swedish CF from a consumption perspective (including embodied emissions of imported products and excluding exports). The estimated CF in 2015 is about 7\% less than the CF estimated in 2010 and the operation EF (4.1 TWh electricity) is about $9 \%$ less.

The CF of the Swedish E\&M sector in 2015 is estimated to about 0.75 Mtonne $\mathrm{CO}_{2}$-eq (80 kg per capita, $0.7 \%$ of Sweden's CF) which is nearly $20 \%$ less than the CF estimated in 2010 and the operation EF (2.8 TWh electricity) is about $10 \%$ less. 
The CF of ICT services and E\&M media content production including paper media is about 0.45 Mtonne $\mathrm{CO}_{2}-$ eq $(0.4 \%$ of Sweden's CF) which is slightly less than the estimated CF of 0.5 Mtonne $\mathrm{CO}_{2}$-eq in 2010 and the operation EF (0.3 TWh electricity) is just slightly higher.

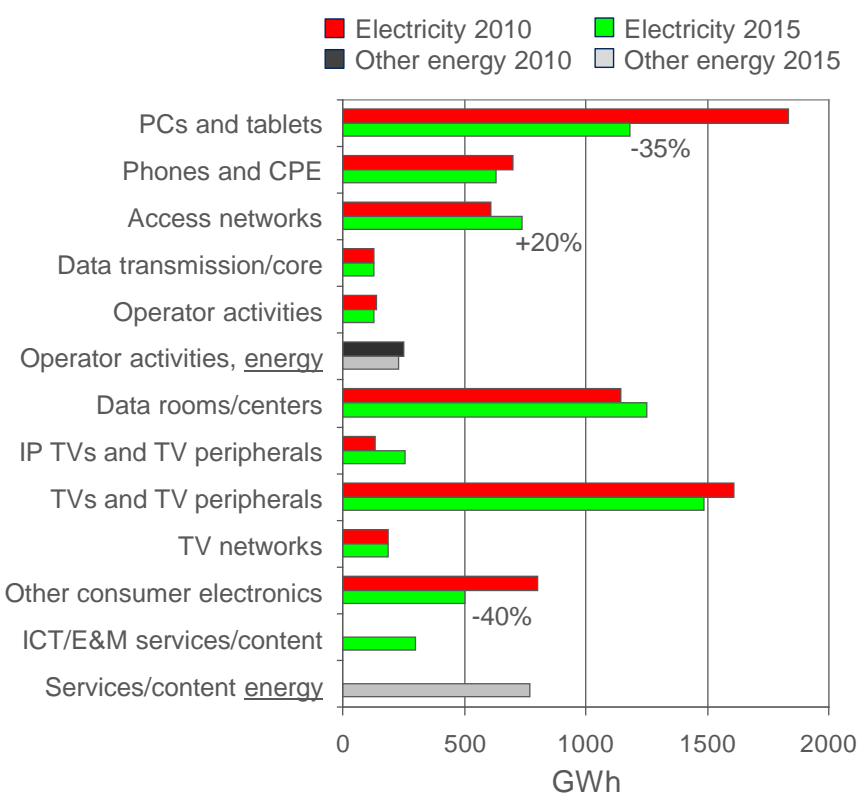

Figure 2 The energy footprint of the ICT and E\&M sectors in Sweden 2015. Paper is not included as no qualitative good energy data exist but the energy footprint is rather small (see carbon footprint estimates for paper in Figure 4 and 5).

Total CF results are presented in Figure 3. The figure illustrate also the importance of the electricity mix.

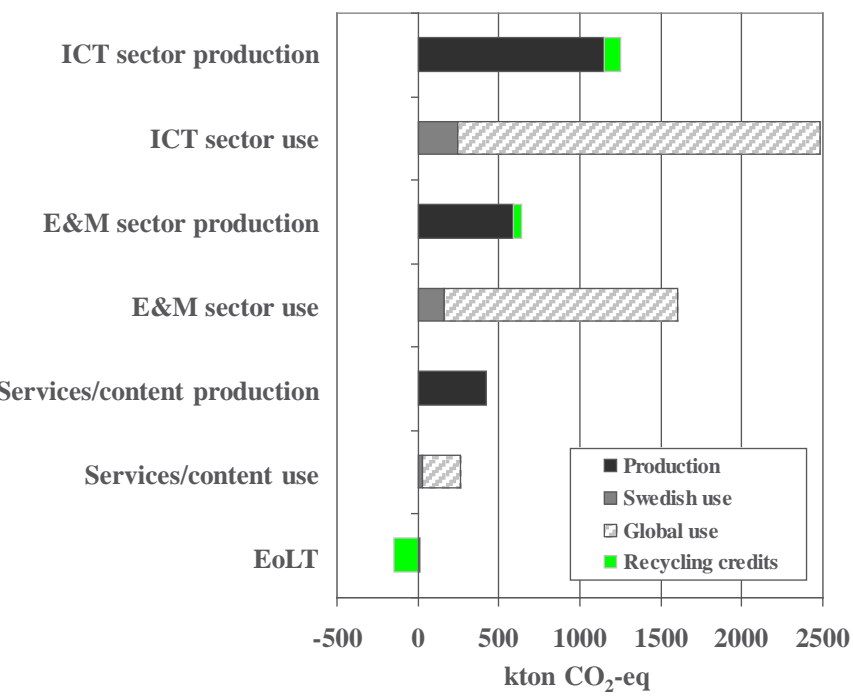

Figure 3 The carbon footprint of the ICT and E\&M sectors in Sweden 2015.

The results for Sweden are strongly influenced by the lowcarbon Swedish electricity mix (mainly based on hydro- and nuclear power production with a growing share of windpower). If the Swedish electricity mix $\left(0.06 \mathrm{~kg} \mathrm{CO}_{2}\right.$-eq for whole life cycle) is changed to a world average mix $(0.6 \mathrm{~kg} \mathrm{CO}$-eq) and everything else is kept the same, the total CF would be about 6 Mtonne instead of just about 2.6 Mtonne.
More detailed carbon footprint results for Sweden are presented in figure 4. Similar as in the 2010 study the largest part of the CF in Sweden is related to the production of user equipment abroad, especially PCs for the ICT sector and TVs for the E\&M sector.

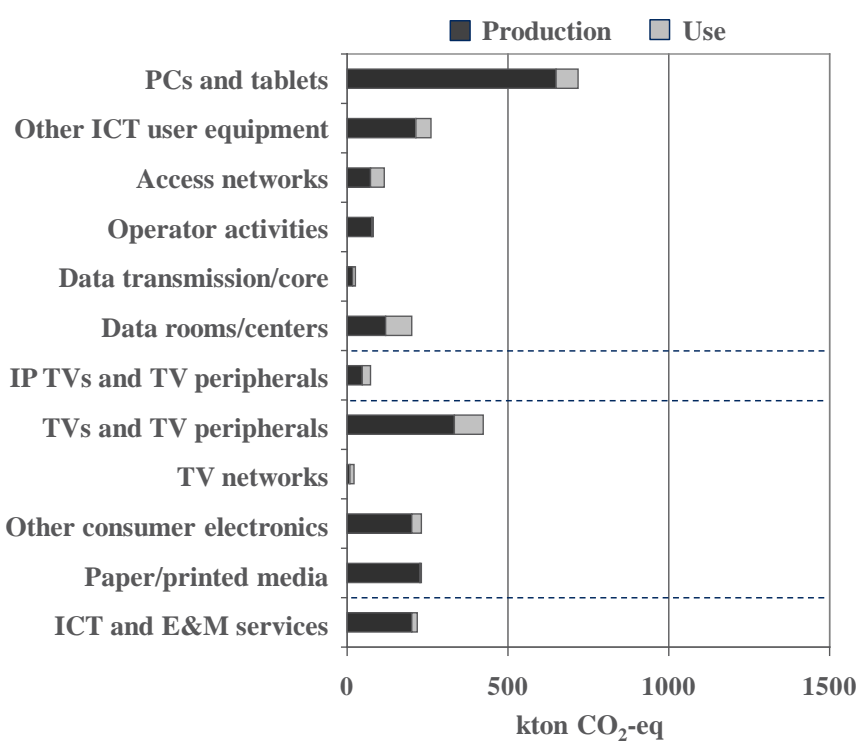

Figure 4 The carbon footprint of the ICT and E\&M sectors in Sweden 2015.

Figure 5 shows what happens if the Swedish electricity mix used in Figure 4 is replaced by a world average mix. Everything else is kept the same.

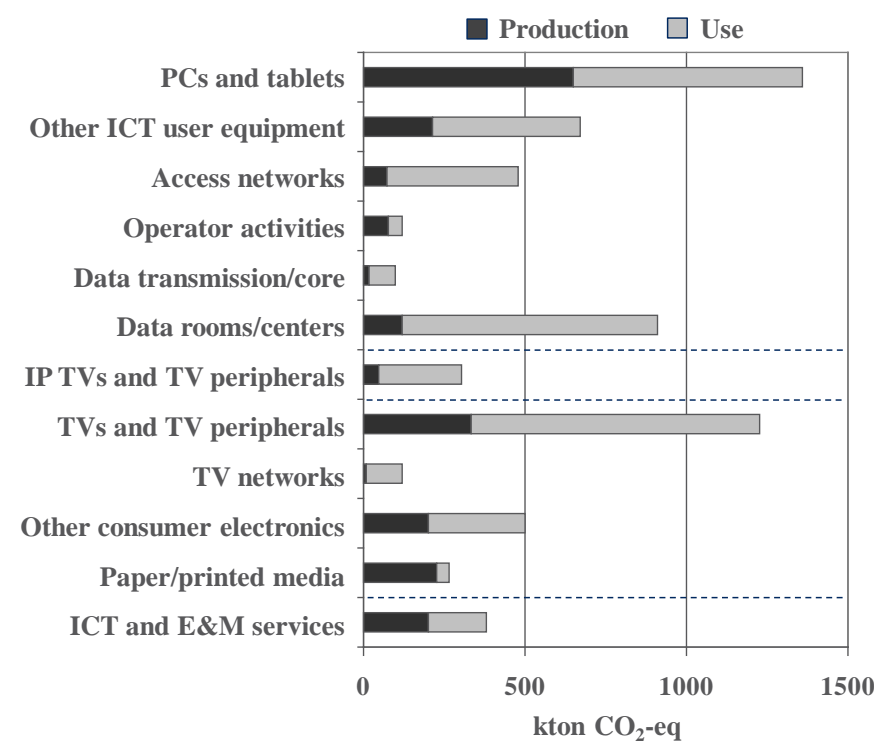

Figure 5 The carbon footprint of the ICT and E\&M sectors in Sweden 2015. Swedish Electricity mix replaced by World average electricity mix.

IPTV is reported separately in Figure 2, 4 and 5 as it can be argued whether IPTV should belong to the ICT or the E\&M sector. Many of the TV peripherals and other consumer electronics have built in communication ability and it can also be argued to what sector they should belong. In this study Hardware (HW) has been allocated based on type and its main use and not based on how much it is used for "ICT" or "E\&M". 

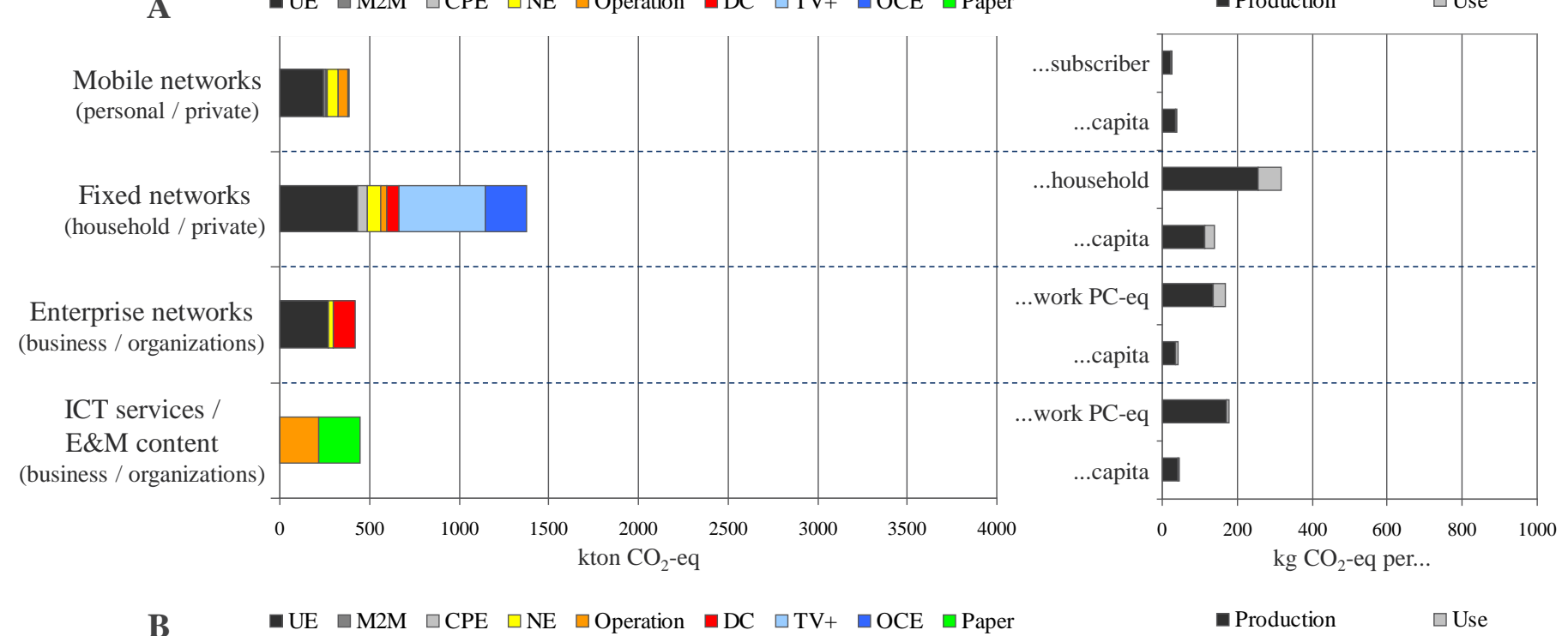

B

UE $\square$ M2M $\square \mathrm{CPE} \square \mathrm{NE} \square$ Operation $\square \mathrm{DC} \quad \square \mathrm{TV}+\square$ OCE $\square$ Paper

- Production

$\square$ Use

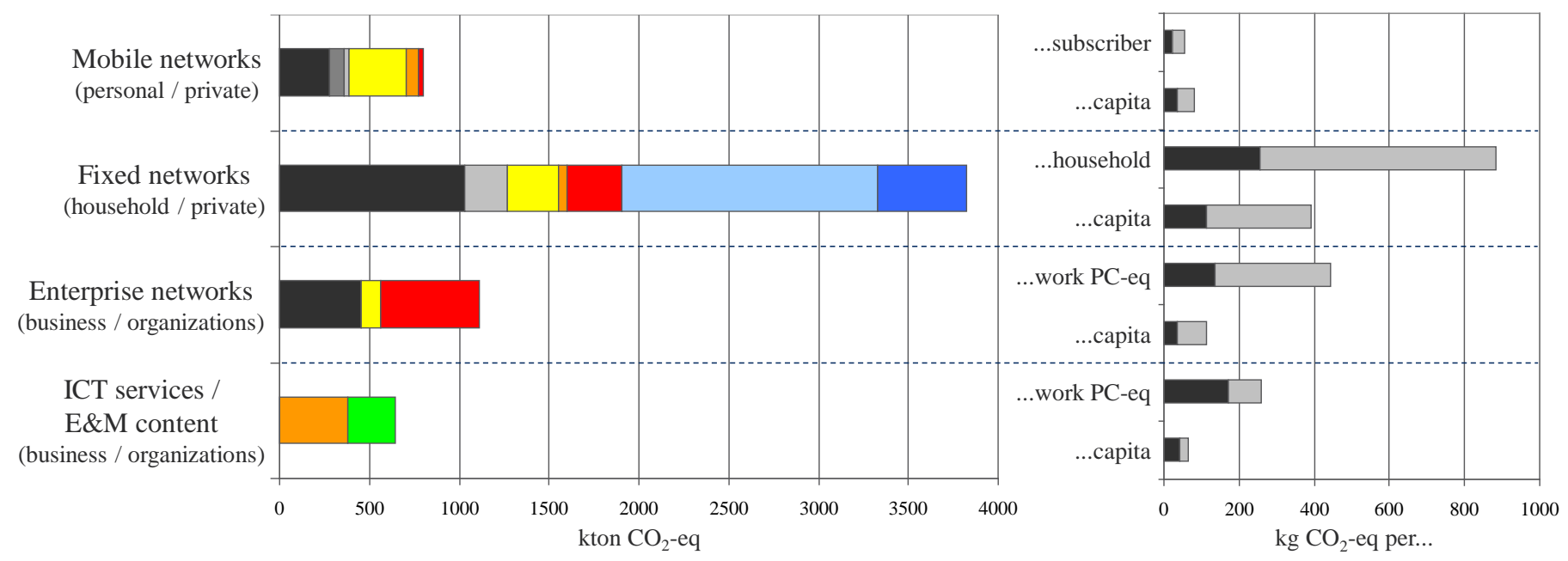

Figure 6 The carbon footprint per technology and private / business / organization subsector and the carbon footprint per subscriber, household and per work PC-eq in Sweden with the Swedish electricity mix (A) and with a world average electricity mix (B). All subsectors are also normalized per capita in Sweden 2015. UE = User equipment, M2M = Machine to machine, CPE = Customer premises equipment, NE = Network equipment, Operation activities, DC = Data rooms/centers, $\mathrm{TV}+$ also includes TV peripherals, OCE = Other consumer electronics, Paper includes all paper and printing equipment.

\section{Results per technology, subscription/user or line/household}

The ICT and E\&M sectors can be split up into a few distinct subsectors. The chosen subsectors are slightly different compared to the primary subscription services presented in the 2010 study. The subsectors chosen this time is mobile networks ("personal"), fixed networks ("household"), enterprise networks ("ICT/E\&M workplace") and ICT services and E\&M content production (also "ICT/E\&M workplace”). The results are allocated to each major technology area and can also be viewed as allocated to "personal", "household" or "workplace" use. All results are also normalized per capita in Sweden and presented with a Swedish and a global average electricity mix, see Figure 6.

The carbon footprint is largest for households and originates from PCs and TVs as explained earlier. The carbon footprint per household is about $330 \mathrm{~kg}$ in Sweden and becomes nearly $900 \mathrm{~kg}$ with a global average electricity mix.
M2M devices have been allocated by technology area to mobile networks (Figure 6) despite one of the main services is so called smart metering related to households. The share of SMS, data traffic and subscription revenues are low for M2M and its part can easily be subtracted from Figure 6 to make the mobile part only equal to personal use. Without M2M, the carbon footprint per mobile subscriber is about $25 \mathrm{~kg}$ or about $33 \mathrm{~kg}$ per capita and comes mainly from the production of smartphones abroad. With a global average electricity mix the corresponding CFs become $50 \mathrm{~kg}$ respectively $65 \mathrm{~kg}$.

The CF per work PC is about $170 \mathrm{~kg}$ in Sweden and becomes nearly $450 \mathrm{~kg}$ with a global average electricity mix. ICT services and E\&M content production sums up to about $180 \mathrm{~kg}$ per work PC in Sweden and $250 \mathrm{~kg}$ globally.

\section{HISTORICAL FOOTPRINTS AND FUTURE PROJECTIONS}

The historical footprints of the ICT sector were first presented in [3] and a more detailed study of the year 2010 was 
published in 2014 [2]. Telia has been measuring and estimating their footprints since the early 1990's but this is the first time the historical and current footprints of both the ICT and E\&M sectors for the whole of Sweden are presented together with future projections until 2020, see Figure 7.
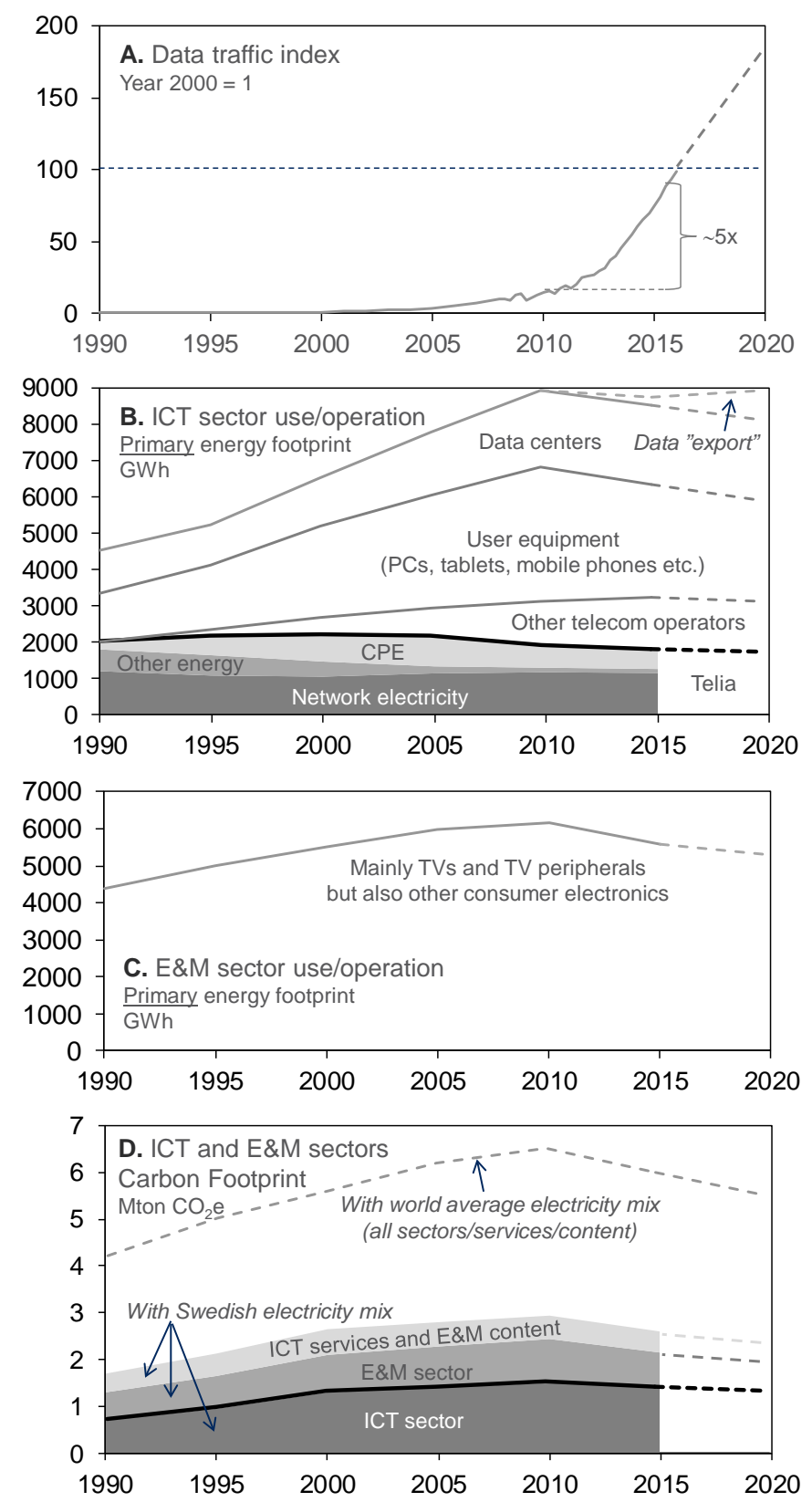

Figure 7 Data traffic (A), energy footprint of the ICT (B) and E\&M (C) sectors and total combined carbon footprint (D) in Sweden from 1990 to 2015 including future projections until 2020. The energy footprint is defined as only use/operation and defined as: Primary energy $=$ Electric energy $* 2$ (average conversion-factor for the nuclear and hydro mix in Sweden)

Telia's own energy consumption in Sweden has actually decreased since 1990 despite the transformation from a state owned PSTN operator with nearly 6 million telephone lines in 1990 to the 10 million fixed and mobile broadband subscriptions and business data operator they are today.
The total data traffic increased about 15 times between 2000 and 2010 and has increased a further 6 times from 2010 to 2015. Despite the continuing exponential increase in data traffic the energy and carbon footprints now decreases in Sweden from a peak around 2010.

The energy footprint is defined as only use/operation and defined as primary energy consumption which means that secondary electric energy is converted to primary energy. This conversion-factor is about 2 in Sweden but as high as about 3 in the world on average. Energy for extraction, production and distribution of fuels and higher forms of energy like electricity is included in the use/operation energy footprint but the so called embodied energy is not included due to lack of data for the production stage.

The energy footprint for the ICT sector increased about 2 times from 1990 to 2010. The main reason for this was the increased use of PCs (desktops) in Swedish homes. Based on older energy investigations by the Swedish Energy Authority data centers, or data halls as they were called, showed that they consumed a substantial amount of energy already during the 1990's. The energy footprint of the E\&M sector has shown a more moderate increase since 1990 (1.4x) as the use of TVs and TV peripherals was already at a high level in 1990, mainly due to old CRT technology and poor energy performance. Both the ICT and E\&M sectors energy footprints have since 2010 decreased with about $10 \%$.

The carbon footprint trends are more related to the so called embodied footprint of all ICT and E\&M equipment imported to Sweden and the reason for the recent decrease is explained by the drop in sales of first of all PCs and TVs but also improvements in the production stage. The low-carbon Swedish electricity mix make the use/operation stage less relevant but when the Swedish mix is changed to a world average mix the trend of decreasing footprints hasbecome even clearer. The main reason for the decrease is the achieved improvements in equipment energy consumption and that the usage is changed to smaller personal portable devices such as tablets and smartphones.

In order to make sound future projections the history and current situation have to be understood. There are several projections and "what if scenarios" that estimate the future footprints of the ICT sector as an exponential increase based on data traffic, for example [11]. This study shows that the opposite is currently seen in Sweden. The footprints are a function of first of all types of user devices, their usage, total volume and numbers in use at the same time (which is limited in contrast to "unlimited" data traffic).

In addition, it is important to remember that the technology development in the ICT sector is not static. Even older technologies are developed leading to more up to date and energy efficient solutions. I.e. Older PSTN is replaced by VoIP or $2 \mathrm{G}$ and by that changes the total ICT infrastructure and footprint giving the same functionality and more but without increasing the footprint of the ICT sector as such. These facts seems too often been forgotten by many researchers. 


\section{DISCUSSION}

The results show a decrease in both energy consumption (energy footprint) and carbon footprint. Sale statistics show that most device subsectors decreases, both in terms of revenue and in terms of device numbers. Only smartphones show a larger increase in 2015 and even tablets have gone from increasing to decreasing.

The waste collection in Sweden shows that the total weight of consumer electronics also goes down but the device numbers have started to increase slightly, mainly due to various smaller household appliances rather than an increasing volume of collected ICT and E\&M devices (see national statistics [26]). Based on current and recent annual sales it can be estimated that the trend of decreasing waste of "IT, telecom and office equipment" will continue and that "TV, audio and video equipment" will also start to decrease. New total figures points to a 7\% decrease in collected WEEE by weight in 2015 [27] but no detailed figures about fractions have yet been released.

The main reason for the change can probably be attributed to an increase in number of smartphones and tablets and changed user behavior. This has resulted in an increased use of these devices instead of using traditional PCs and TVs. Statistics for the period 2005-2015 shows that the number of sold PCs (especially desktops) and TVs for the first time decreases steadily and this is the main reason for the carbon footprint decrease.

The trend of decreasing energy consumption since around 2010 have also been identified in a US study (-13\%) [8] and in a German study (-15\%) [9]. The scope in these studies are a bit different, e.g. embodied footprints are not included. The German study projects an increasing energy footprint in the future (2020-2025) even if the EF in a shorter perspective decreases (2010-2015) and is projected to further decrease until 2020. A third study of ICT in Japan [12] projects that the EF as a worst case scenario increases in the future and more.

The CF per capita presented for the ICT and E\&M sector in this study is slightly higher, 220 vs $200 \mathrm{~kg} \mathrm{CO}_{2}$-eq, compared to the results for the "IT and communication" sector presented by SEI [24]. The SEI study (that also include TVs) uses trade I/O-data for Sweden combined with emission factors for abroad production but is not as detailed as in this study. Still the result is similar.

Based on recent data center and data traffic trends, several new large data centers have been located in the Nordics in general and in Sweden in particular (i.e. Facebook in Sweden, Google in Finland and Apple in Denmark). It can be assumed that the Nordic region will change from being a large data consumer to an actual net producer of data for the rest of Europe (and globally).

Due to the preferable Nordic electricity mix whit a high degree of non-fossil based electricity it can be stated that datacenters that is located in this region will reduce the total ICT carbon footprint compared to the use of data centers in other regions (i.e. Central Europe).
The Swedish ICT users usage of local data center services have been taken into account and credited to the Swedish ICT sector in the study as a reduction of the carbon footprint related to Swedish users. However, there is still a small part of data center services that are consumed in Sweden using data centers abroad, data centers that operate on world average electricity with a much higher emissions factor.

At the same time parts of the Swedish data center services are used by users abroad and their share have been subtracted from the Swedish footprint. The footprint from abroad can possibly in the future be turned into a net reduction of the footprint if more data center services are located to the Nordic region. However, such a "negative" footprint can be hard to get acceptance for and communicate. The same principle applies to other industries that also on a high degree is dependent on Swedish electricity. However, no such "credit” or subtraction have been applied in this study.

In order to decrease the CF in Sweden the focus should be on the embodied footprint related to production of devices abroad. To use devices longer (longer life time) would also decrease the footprint as fewer devices need to be produced and imported to Sweden. Applied on a global perspective energy usage of user equipment is still the first area to focus on if the aim is to reduce future CF.

\section{CONCLUSIONS}

The energy and carbon footprints of the ICT and E\&M sectors is decreasing in Sweden from a top at around 2010. The total carbon footprint is about $1.9 \%$ (1.2\% ICT, $0.7 \%$ E\&M) of Sweden's total carbon footprint using a consumption perspective (production abroad included) and the decrease from 2010 is around 10\%. Historically the footprints have been increasing since real measurements begun first at around 1990 but now it seems that a 20 years old trend has been broken and as Sweden is world leading in many ICT and E\&M categories this is an important observation.

The carbon and energy footprints are mainly related to number and types of user devices put on the market and their usage. But not as much related to networks and data traffic volumes. When the carbon footprint is calculated based on the world average mix instead of using Swedish Electricity mix the declining trend becomes even clearer. This is due to better energy performance of new devices and a shift in use from PCs and TVs to tablets and smartphones with a low energy consumption, mainly due to smaller screens.

ICT services and E\&M content production have, for the first time been estimated. The resulting carbon footprint has been estimated to about $0.4 \%$ of Sweden's carbon footprint including paper and printing. Also the paper and printing sector shows a decreasing trend.

\section{ACKNOWLEDGEMENT}

The authors wish to thank all employees at Telia who have contributed with data and measurements. A similar thanks goes to colleagues and friends that supported us at Ericsson and CESC (Centre for Sustainable Communications at KTH). In addition all external sources, mainly operators, suppliers and contractors. We owe you! 


\section{REFERENCES}

[1] World Economic Forum. 2016. Available at [accessed in February 2016]: $\quad$ http://www.weforum.org/agenda/2016/01/what-are-the-topglobal-risks-for-2016

[2] Malmodin, J. et al. 2014. Life cycle assessment of ICT - Carbon footprint and operational electricity use from the operator, national and subscriber perspective in Sweden. Journal of Industrial Ecology, 18 (6), 829-845.

[3] Lundén, D. and Malmodin, J. 2013. Changes in environmental impacts over time in the fast developing ICT industry. The 6th International Conference on Life Cycle Management (LCM2013), Gothenburg, 26-29 August 2013. Available from [Accessed 23 April 2015]: http://conferences.chalmers.se/index.php/LCM/LCM2013/paper/view/58 $\underline{0 / 180}$

[4] Malmodin, J., Moberg, Å., Lundén, D., Finnveden, G., and Lövehagen, N. (2010) Greenhouse gas emissions and operational electricity use in the ICT and Entertainment \& media sectors. Journal of Industrial Ecology, 14(5), 770-790.

[5] GeSI (Global eSustainability Initiative). 2008. Smart 2020: Enabling the low carbon economy in the information age. A report by The Climate Group on behalf of GeSI.

[6] GeSI. 2012. Smarter 2020: The role of ICT in driving a sustainable future. A report by Boston Consulting Group on behalf of GeSI. Available at [accessed in February 2016]: http://gesi.org/SMARTer2020

[7] GeSI. 2015. \#SMARTer2030 ICT Solutions for the $21^{\text {st }}$ Century Challenges. A report by Accenture on behalf of GeSI. Available at [accessed in February 2016]: http://smarter2030.gesi.org/

[8] Urban, B. et. al. 2014. Energy consumption of consumer electronics in U.S. homes in 2013. Final report to the consumer electronics association (CEA). Fraunhofer USA center for sustainable energy systems. June 2014.

[9] Federal Ministry for Economic Affairs, Germany. 2015. Development of ICT-related electricity demand in Germany (report in German), commissioned by the Federal Ministry for Economic Affairs and Energystudy by the Fraunhofer Institute for Reliability and Microintegration and the Borderstep Institute.

[10] tefficient. 2016. 5 GB per any SIM and month no longer a utopia - if price is right. Industry analysis 1:2016, Mobile data usage 1H 2015. Available at [accessed February 2016]: http://media.tefficient.com/2016/01/tefficient-industry-analysis-1-2016mobile-data-usage-and-pricing-1H-2015.pdf

[11] Andrae, A. S. G. and Edler, T. 2015. On Global Electricity Usage of Communication Technology: Trends to 2030. Challenges 2015, 6, 117157; doi:10.3390/challe6010117

[12] Kishita, Y. et. al. 2016. Describing Long-Term Electricity Demand Scenarios in the Telecommunications Industry: A Case Study of Japan. Sustainability 2016, 8, 52; doi:10.3390/su8010052

The following reports are reocurring every half-, full- or bi- year. Only the latest report or reports are referenced here due to the limited format for this paper:

[13] PTS (The Swedish Post and Telecom Agency). 2015. The Swedish Telecommunications Market 2014, PTS-ER-2015:19. Available at [accessed October 2015]: www.statistics.pts.se/start en

[14] PTS (The Swedish Post and Telecom Agency). 2015. The Swedish Telecommunications Market First Half Year 2015 - PTS-ER-2015:28. www.statistics.pts.se/start_en/

[15] SCB (Statistics Sweden). 2015. Telecommunications 2014, SCB (in cooperation with PTS).

[16] SCB (Statistics Sweden). 2016. Population statistics. Available at [accessed April 2016]: $\underline{\text { http://www.scb.se/en /Finding- }}$ statistics/Statistics-by-subject-area/Population/Populationcomposition/Population-statistics/

[17] Electronics Association. 2016. Rateko. Consumer Electronics Technical and Commecial Organizations. Journal with 6 issues every year including sale statistics. In cooperation with the Mobile Phones Association. Available at [accessed January 2016]: www.rateko.se

[18] Swedish Radio and TV Authority. 2015. Media Development 2015, ISSN 1404-2819, ISBN 978-91-980489-6-4.
[19] The Swedish Forest Industries. 2015. The Forest Industry - Facts and Figures, Industry Statistics 2014, Available at [accessed November 2016]: www.forestindustries.se/statistics

[20] Swedish Work Environment Authority. 2014. The Swedish work environment 2013, Work Environment Statistics Report 2014:3, ISSN 1652-1110.

Normal references continued:

[21] Zimmermann, J. P. 2009. End-use metering campaign in 400 households in Sweden. Assessment of the potential of electricity savings. Enertech. Eskilstuna: Swedish Energy Agency. Also includes historical data.

[22] Swedish Energy Agency. 2009. Energy statistics for non-residential premises 2007. Also includes historical data. ES 2009:05.

[23] Peters, G., Solli, C. 2010. Global carbon footprints. Nordic Council of Ministers 2010. ISBN 978-92-893-2159-4

[24] Stockholm Environment Institute (SEI). assignment from Cogito, Global miljöpåverkan och lokala fotavtryck - analys av fyra svenska kommuners totala konsumtion (in Swedish), SEI report, Author: Katarina Axelsson, 2012. (ISBN: 978-91-86125-39-4)

[25] Swedish IT and Telecom Companies. 2016. Available at [accessed February 2016]: https://www.itotelekomforetagen.se/

[26] El-kretsen. 2015. Collected and treated WEEE in Sweden 2014. Available at [accessed February 2016]: http://www.elkretsen.se/sitespecific/elkretsen/files/artiklar/statistik_2014.pdf

[27] El-kretsen. 2016. Collected and treated WEEE in Sweden 2015. Available at [accessed April 2016]: http://www.elkretsen.se/sitespecific/elkretsen/files/artiklar/statistik_2015.pdf 